
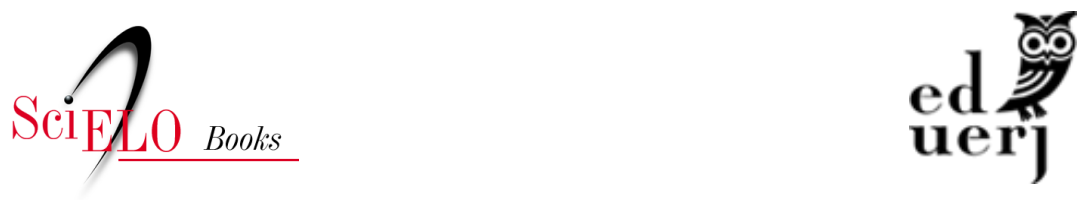

\title{
Capitulo 4 - O Programa Bolsa Família: usos do benefício e sentidos da titularidade
}

\author{
Rosana Salles-Costa \\ Ana Alice Taborda \\ Viviane dos Anjos Maresi, \\ Gilza Sandre-Pereira \\ Mirian Ribeiro Baião
}

\section{SciELO Books / SciELO Livros / SciELO Libros}

SALLES-COSTA, R., TABORDA, A. A., MARESI, V. A., SANDRE-PEREIRA, G. and BAIÃO, M. R. O Programa Bolsa Família: usos do benefício e sentidos da titularidade. In.: SILVA, A. C. F., MOTTA, A. L. B., and CASEMIRO, J. P., eds. Alimentação e nutrição na atenção básica: reflexões cotidianas e contribuições para prática do cuidado [onine]. Rio de Janeiro: EDUERJ, 2021, pp 77-98. ISBN: 978-65-87949-11-6. https://doi.org/10.7476/9786587949116.0005.

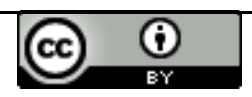

All the contents of this work, except where otherwise noted, is licensed under a Creative Commons Attribution 4.0 International license.

Todo o conteúdo deste trabalho, exceto quando houver ressalva, é publicado sob a licença Creative Commons Atribição 4.0.

Todo el contenido de esta obra, excepto donde se indique lo contrario, está bajo licencia de la licencia Creative Commons Reconocimento 4.0. 


\section{Capitulo 4 \\ O Programa Bolsa Família: usos do benefício e sentidos da titularidade}

Rosana Salles-Costa

Ana Alice Taborda

Viviane dos Anjos Maresi,

Gilza Sandre-Pereira

Mirian Ribeiro Baião

Este capítulo tem como proposta discutir os usos do benefício do Programa Bolsa Família (PBF) e os sentidos da titularidade, na ótica dos participantes. Para auxiliar na discussão, são apresentados resultados de dois estudos que fazem parte do projeto "Estudo longitudinal de famílias atendidas pelo Programa Bolsa Família no município de Duque de Caxias". O trabalho foi realizado pelo Grupo de Pesquisas sobre Segurança Alimentar e Nutricional em Duque de Caxias - SANDUC -, que apresentou três vertentes de investigação: 1) o estudo quantitativo; 2) o estudo qualitativo; e 3) o estudo de análise política local, voltados a compreender o contexto do PBF no município.

Os estudos aqui retratados ( $\mathrm{A}$ e $\mathrm{B}$ ) correspondem ao componente dois da pesquisa, conduzidos por meio da abordagem qualitativa a partir das técnicas de entrevista semiestruturada e observação. $\mathrm{O}$ referencial analítico fundamentou-se na perspectiva interpretativista e se utilizou da análise de conteúdo temática, conforme proposto por Bardin (2011), adaptada por Minayo et al. (2012). Ambos os estudos ocorreram no distrito de Campos Elíseos, município de Duque de Caxias/RJ. O estudo A ocorreu no ano de 2014, sendo entrevistadas dez mulheres titulares do PBF, nos Centros de Referência de 
Assistência Social (CRAS), no Centro de Apoio à Saúde da Família e no Ambulatório Paroquial Irmá Beta. O estudo B foi realizado em 2016, por meio de entrevistas com cinco homens e cinco mulheres, titulares do PBF, realizadas no domicílio dos titulares.

\section{O Programa Bolsa Família como política de transferência de renda no Brasil}

Nas últimas décadas, a pobreza tem sido objeto de intenso debate político e acadêmico no Brasil. Profundas transformações nas dinâmicas econômica, social e política do país trouxeram novos desafios para a construção de intervenções públicas capazes de superar as formas tradicionais de privação no contexto rural e também reduzir as situações de vulnerabilidade social e segregação no espaço urbano. A chamada pobreza extrema emerge como a face mais dramática de processos contraditórios e heterogêneos marcados pela precariedade das condiçóes de trabalho, da renda, da moradia, do acesso a bens e serviços e do isolamento social.

Associadas à pobreza, questóes sociais, culturais e ambientais influenciam na determinação da saúde da população, no processo de adoecimento e na consolidação do cuidado integral. Esse cenário, representa desafios para o alcance da promoção da saúde, sendo a intersetorialidade uma necessidade urgente (Rigon et al., 2016).

As ações governamentais na saúde e, em especial, na área de alimentação e nutrição, como a Estratégia Saúde da Família e a Política Nacional de Alimentação e Nutrição (PNAN), buscam construir e consolidar uma gestão e atuação intersetorial. A PNAN tem se mostrado elemento chave para a Política Nacional de Saúde e Política e Sistema Nacional Segurança Alimentar e Nutricional junto ao SUS, em busca da superação da pobreza e da equidade (Alaves e Jaime, 2014). Além disso, as reflexôes sobre a importância do cuidado integral na atenção nutricional no âmbito do Sistema Único de Saúde (SUS), respeitando as singularidades do sujeito e a complexidade do 
processo saúde-doença, ampliam a visão dos profissionais que atuam na área da alimentação e nutrição (Alaves e Mattos, 2019).

Assim, no Brasil, a agenda das políticas públicas de proteção social, combate à pobreza e promoçáo da saúde e da Segurança Alimentar e Nutricional (SAN) tem incorporado, também, o debate sobre os programas de transferência condicionada de renda (PTCR). Esses programas se destinam às famílias que vivem em contextos adversos e cuja condição nutricional é impactada por múltiplos constrangimentos, tais como as dificuldades de acesso e consumo de alimentos em quantidade e qualidade adequados (Burlandy, 2007).

Cabe destacar que os PTCR atuam como eixo central das políticas de combate à pobreza na América Latina e Caribe, com expressivo crescimento em cobertura populacional. Apresentam particularidades, conforme cada país, e o principal objetivo consiste na melhoria das condiçôes de vida de famílias pobres, em curto prazo e, em longo prazo, na superaçáo do ciclo de pobreza com a transferência de renda (CEPAL, 2011). Em geral, esses programas trazem em comum a focalização das ações para as populaçôes mais pobres e a recomendação de sua titularidade para as mulheres, tornando-as responsáveis pelo recebimento do benefício monetário na maioria das famílias participantes. Esse ponto será retomado mais adiante, em razão da sua importância no presente capítulo. Outra característica dos PTCR é a associação do benefício com o cumprimento de condicionalidades nas áreas da saúde e de educação por parte dos participantes (Brasil, 2004).

Em 2003, o governo federal brasileiro optou pelo investimento em PTCR, unificando outros tipos de intervenções, tais como a distribuição de alimentos e os programas de cupom alimentação (anteriormente implementados em alguns estados do país), em um único programa denominado Programa Bolsa Família (PBF).

$\mathrm{O} P B F$ é destinado às famílias em situaçóes de pobreza extrema com renda de até $\mathrm{R} \$ 89,00$ reais mensais, por pessoa, e famílias com renda por pessoa entre $\mathrm{R} \$ 89,01$ e $\mathrm{R} \$ 178,00$ mensais, desde que 
tenham menores de 17 anos (MDS, 2019). Cabe ressaltar que, na época de realização dos estudos, os pontos de corte de renda para ingresso no programa eram de $\mathrm{R} \$ 77,00$ (ano de 2014) e $\mathrm{R} \$ 85,00$ (ano de 2016), por pessoa da família, respectivamente para os estudos $A$ e $B$. De acordo com os princípios básicos estabelecidos pelo governo federal, em 2003, o PBF tem como objetivos principais (i) a redução da pobreza monetária e (ii) a ampliação do acesso à educação e aos serviços de saúde por meio do incentivo ao cumprimento de condicionalidades ou contrapartidas sociais (MDS, 2019).

Com relação às condicionalidades do programa, o auxílio monetário foi associado à participação das famílias em três eixos saúde, educação e assistência social. Na saúde, que abarca o nível da Atenção Básica, as gestantes, as nutrizes e as crianças de até seis anos das famílias participantes devem comparecer, respectivamente, às consultas de pré-natal e de pós-natal e ao acompanhamento nutricional, assim como manter o calendário de vacinação atualizado, além de frequentar atividades educativas sobre saúde e nutrição nas unidades básicas de saúde. Quanto à educação, é exigida a frequência escolar de $85 \%$ para crianças e adolescentes de até 15 anos e de $75 \%$ para adolescentes na faixa de 15 a 17 anos. Por fim, na área de assistência social, as famílias devem ser atendidas por programas socioassistenciais, implementados pelos CRAS. Cabe ressaltar que o não cumprimento das condicionalidades pode implicar a suspensão do pagamento e até mesmo o cancelamento do benefício (BRASIL, 2004).

Acrescenta-se que programas complementares devem ser ofertados pelos três níveis de governo (federal, estadual e municipal) como forma de contribuir para a emancipação das famílias, ainda que estudos indiquem fragilidade dessas açóes em alguns contextos (Rosinke et al., 2011). Portanto, a perspectiva de mudança na vida das famílias cadastradas no PBF envolve, por um lado, impactos no consumo a partir do uso do benefício monetário e, por outro, o maior acesso às açóes e serviços públicos, propiciados supostamente 
pela condicionalidade, ou pelo conjunto de programas complementares que venham a incidir sobre as famílias em questấo.

Após síntese sobre o PBF, apresentaremos dados dos estudos $\mathrm{A}$ e $\mathrm{B}$ com vistas à compreensão sobre o uso do benefício pelas famílias na superação da pobreza e sobre a titularidade na perspectiva dos participantes.

\section{Uso do benefício do Programa Bolsa Família}

Uma particularidade dos PTCR e, portanto, do PBF é a autonomia concedida às famílias participantes quanto ao uso do recurso financeiro, visto que o benefício concedido se dá em forma de dinheiro, diferentemente dos programas anteriores que vinculavam o benefício a uma despesa específica no seu uso (cesta de alimentos, compra de gás, entre outros).

$\mathrm{Na}$ maioria dos casos, a titular do benefício do PBF é a mulher, cabendo a ela, no contexto familiar, definir o que comprar. Cabe lembrar que a literatura nacional sugere fortemente que a mulher é a principal responsável pela administração do benefício, mesmo nos casos em que ela vive com marido ou companheiro (Santos et al., 2015; Mariano e Carloto, 2013; Rego e Pinzani, 2013; Pires, 2012; Ibase, 2008; Mariano, 2008). Para corroborar essa afirmativa, podemos exemplificar com uma entrevista, realizada com um homem do estudo B que, apesar de ser o titular do programa, para ele havia um entendimento implícito de que caberia à sua companheira gerir o dinheiro recebido. Outro aspecto interessante observado na pesquisa $B$ se refere ao fato de os homens entrevistados sentirem necessidade de justificar o motivo de serem eles os titulares do benefício, quer fosse pela presença de filhos ou por algum motivo de doença. Na verdade, mostravam-se constrangidos com a titularidade do programa, consideravam também importante receber o benefício pelo maior poder de compra que 
este proporcionava. Outras questóes sobre a titularidade serão abordadas no item a seguir que tratará dos sentidos da titularidade.

Ainda sobre o uso do benefício, acrescentamos que, uma vez que o Estado condiciona aos participantes a frequência escolar, o acompanhamento nutricional e de saúde dos filhos e a realização de exames pré-natais para as gestantes, as condicionalidades influenciam decisivamente nos padróes dos gastos do dinheiro pela mulher titular do programa. Ou seja, compreende-se que o uso correto seria aquele feito diretamente para os filhos, com roupas, material escolar e alimentação saudável de acordo com lógica do programa. Assim, a liberdade de decidir como gastar o benefício é acompanhada implicitamente de julgamentos sobre seu uso.

A utilização do benefício é permeada por uma forte "moralidade" e estabelece um "jeito certo" e um “jeito errado" de gastar o dinheiro (Pires, 2012). Entretanto, as questóes relativas ao consumo, sobre como e com o quê se gasta o dinheiro do PBF, é um debate ainda pouco recorrente e que merece um olhar mais atento. A entrada da família no PBF é apenas mais um item das diversas relaçóes sociais que envolvem a condição de vida de cada família e a forma como vivem (Zelizer, 2003). Os contextos de vida de cada família contribuirão para definir o que elas entendem como necessidades, o que, por sua vez, estabelecerá as prioridades e o modo de utilizar os recursos.

As entrevistas realizadas com mulheres em Duque de Caxias indicaram que o uso do benefício tem forte relação com a composição familiar. A presença de crianças nas famílias tende a ser determinante no destino dos recursos do programa. Dessa forma, as mulheres entrevistadas no contexto do estudo A tenderam a escolher produtos que consideravam "melhores" para seus filhos, e as escolhas eram movidas por sentimentos relacionadas ao afeto e ao cuidado, buscando proporcionar, a partir do recebimento do recurso, produtos que não conseguiam adquirir anteriormente. Observamos, então, que famílias que possuíam crianças na sua 
composição utilizavam o benefício na compra de itens/produtos vinculados ao bem-estar e conforto dos filhos. Compravam itens gerais da alimentação, principalmente aqueles percebidos como "especiais para crianças", materiais para educação, roupas, brinquedos e passeios nos quais as crianças das famílias se inseriam.

De fato, o entendimento de que "o Bolsa Família é para as crianças" foi recorrente nas narrativas dos entrevistados que participaram dos dois estudos, como podemos perceber nas falas a seguir:

A prioridade, neste momento, que eu tenho, é a casa, que eu tenho que dar um conforto para os meus filhos (Eloísa, estudo $A$ ).

Foi pro meu filho mesmo [...] o cartão é mais pra ele, tá no meu nome, mas o dinheiro é dele, não é meu (Sandro, estudo $B$ ).

A partir desse entendimento, e dependendo da condição de vida da família, outras necessidades podem ser percebidas, gerando novas demandas, como a compra de medicamentos, pagamento de internet e de consultas médicas ou exames e, até mesmo, em melhorias da estrutura da moradia (colocação de piso, reparos de problemas decorrentes de chuvas fortes, entre outras).

No entanto, a compra de alimentos destacou-se como prioridade no cotidiano das famílias participantes estudadas em Duque de Caxias. Nas entrevistas avaliadas, ficou evidente que, a partir do recebimento do benefício, os alimentos considerados "básicos", como o arroz, o feijão e a carne, passam a ser adquiridos com mais regularidade. É importante ressaltar também que alimentos considerados como "bons para as crianças", como os iogurtes e os refrigerantes, incorporados à significação de "alimento infantil" passaram a ser incluídos, no consumo alimentar das famílias.

A compra de "alimentos infantis", no contexto das entrevistas, pode ser vista como uma forma de "cuidado" com as crianças. Além disso, carregava um sentido de inclusão, de pertencimento a uma sociedade que tem no consumo um valor de distinção social 
(Bordieu, 2007), a partir do fato de que as famílias contempladas pelo PBF podiam escolher o que comprar e podiam pagar pelos produtos escolhidos, ainda que de forma limitada. Para essas famílias, o consumo de alimentos de marcas como Mucilon ${ }^{\circledR}, \mathrm{Nescau}^{\odot}$, Danone $^{\circledast}$ e Coca-Cola ${ }^{\circledast}$, citados em diferentes entrevistas, tinham o significado de ascensão social, proporcionado pelo processo de livre escolha e compra de produtos considerados "de qualidade".

Nesse sentido, é importante considerar a influência da publicidade e sua interferência no consumo alimentar da população (Souza e Révillion, 2012). Os produtos alimentares citados acima são derivados de grandes marcas com forte apelo publicitário. Assim, ter a possibilidade de adquirir tais produtos é entendido como uma forma de "dar o melhor" para seus filhos. Um "melhor" que se ancora no valor simbólico que carregam, e não no valor nutricional.

Outra prioridade citada pelas titulares, também relacionada às crianças, foi o gasto do benefício do PBF com o pagamento de creches e escolas, demonstrando, dessa forma, uma necessidade importante no contexto de vida das famílias.

É que aqui na baixada não tem, assim... na minha opinião, uma escola pública pra gente deixar nossos filhos de três, quatro anos. Não sei se você me entende (Joana, estudo $A$ ).

A preocupação com a educação dos filhos, especialmente na primeira infância, era constante no cotidiano das famílias. Esse fato estava associado à percepção dos entrevistados de que a educação pública era deficitária, tanto em termos de oferta quanto de qualidade do ensino.

Interessante perceber que, quando não havia presença de crianças nas famílias, o uso do benefício era destinado a outros fins, como compra de utensílios domésticos ou mesmo uso em tratamentos estéticos (cortar o cabelo ou comprar um esmalte), 
porém com certo constrangimento por não haver, no contexto desses gastos, a conotação do uso do dinheiro vinculado a uma criança. $\mathrm{O}$ constrangimento se tornava maior quando o recurso do $\mathrm{PBF}$ se destinava à outra finalidade, mesmo havendo uma criança na família, configurando o entendimento do dinheiro gasto como "desvinculado da criança". É o caso de Laura, que vive com o companheiro e a neta e que relatou desta forma a compra de uma máquina de lavar com o dinheiro do benefício.

[...] eu fiz também uma bobeira... eu tava precisando de uma máquina para lavar roupa, eu fui lá e tirei essa máquina, que tá dando um pau na consciência agora para pagar essa máquina. Tô aguardando esse dinheirinho para eu pagar a máquina [silêncio] é o que eu fiz, né? a gente só gasta o que pode, né? eu não devia ter feito [chorando] (Laura, estudo $A$ ).

Ao contar sua história, ela falou de uma vida sofrida e das dores nas costas, fruto dos muitos anos trabalhando na rampa do Aterro Sanitário de Jardim Gramacho, como uma espécie de justificativa por "precisar" de uma máquina de lavar. Envergonhada, já no final da entrevista, se emocionou e chegou a pedir desculpas pelo "erro cometido", afirmando que o dinheiro não era para ser utilizado para tal finalidade. Assim, fica claro, na entrevista de Laura, o que Pires (2012) chamou de "jeito certo" e "jeito errado" de usar o benefício, a que nos referimos anteriormente. $\mathrm{O}$ dinheiro na mão e a suposta liberdade de escolha sobre o que comprar esbarram, finalmente, num julgamento moral que, vindo de fora de forma implícita, é internalizado pelos participantes.

Embora a alimentação seja considerada a maior prioridade na utilização do recurso do PBF, a compra de alimentos básicos significa o atendimento a necessidades em nível de sobrevivência. Para os entrevistados, o PBF deveria prever um auxílio que fosse além de possibilitar somente a compra de alimentos, ou seja, para 
que efetivamente houvesse uma perspectiva de melhoria de suas vidas, como revelado na reflexão de uma das entrevistadas.

[...] mas hoje em dia ninguém pode mais pensar [só] no arroz, feijão e um pó de café e no óleo [...] (Sofia, estudo A).

O discurso demonstrou a insatisfação da participante com o programa. Com o dinheiro do $\mathrm{PBF}$, somente a sobrevivência é atendida, apenas o básico pode ser comprado. Assim, a transferência de renda se manifesta como uma simples "oferta de alimentos", ou, como explicitado na fala de outras entrevistadas: "é uma ajuda". Sofia, na sua entrevista, sugeriu que o PBF poderia auxiliar mais se promovesse qualificação profissional e empregos aos seus participantes. Nossa interpretação dessa entrevista é que apenas possibilitar a compra de alimentos não é suficiente para que as famílias saiam da situação de pobreza, uma vez que ingressam no programa.

O sentido de "ajuda" apareceu nas entrevistas dos dois estudos realizados em Duque de Caxias e é observado também no estudo de Pires (2012), com participantes do PBF em Campinas, São Paulo. Para os titulares de Duque de Caxias, além dessa noção, a análise é de que há também a conotação de "a ajuda ser pouca", ou seja, de náo ser suficiente para atender as novas demandas que se tornam mais visíveis para eles quando a necessidade mais básica é atendida. Desse modo, observamos que os participantes do programa começam a perceber direitos que não eram compreendidos por eles antes da entrada no PBF. Ou seja, ao longo do tempo, as famílias vão percebendo, por exemplo, o direito de ter o filho em uma boa escola, de comprar uma máquina de lavar, de comprar uma roupa nova e não viver somente em nível de subsistência. 


\section{Os sentidos da titularidade do PBF}

Para falar dos sentidos da titularidade do programa, retomaremos a questáo de que o PBF oficialmente prioriza as mulheres para a titularidade do benefício, por considerá-las principais responsáveis pelo cuidado e bem-estar dos membros das famílias (Ibase, 2008).

Quando avaliamos entrevistas entre titulares homens do estudo B, a situação relatada por Sandro, titular do PBF, manifestou o quanto essa questão da titularidade feminina era naturalizada. Ao chegar à Caixa Econômica para realizar o saque do benefício, Sandro se sentiu constrangido pelo questionamento da atendente. Ele conta:

Uma vez fui sacar o dinheiro e a mulher falou: 'Ué, mas você recebe o Bolsa Família?' Eu falei: 'Eu não'. 'Ué, mas está no seu nome.' Eu falei: 'mas é porque eu sou o pai dele, mas quem recebe o benefício é ele, eu sei que eu não devo explicação pra você, mas eu não moro sozinho, eu moro com meu filho, meu filho mora comigo'. Daí ela: 'ah, desculpa, eu não sabia'. [...] Ela achou estranho! Por estar no meu nome e eu ser homem e receber o Bolsa Família, ela achou estranho (Sandro, estudo B).

Alguns estudos já têm discutido o papel da mulher como foco da titularidade das políticas sociais e o reflexo na vida das titulares. Dentre eles, alguns consideram que a titularidade feminina nas políticas sociais reforça os papéis tradicionais de gênero, ao reafirmar como femininas as tarefas e as atribuiçôes ligadas à maternidade, ao ambiente doméstico e ao cuidado com a família, o que levaria a minimizar a responsabilidade do homem no cumprimento de tarefas dessa ordem (Mariano e Carloto, 2009; Duque-Arrazola, 2010). Cabe considerar o contraponto de que, para algumas mulheres, a titularidade de um programa social proporcionou a primeira opor- 
tunidade de gerenciar renda, um aumento do seu poder de compra e o reconhecimento de si perante a família e a sociedade, em razão de ser ela a responsável pelo benefício (Duque-Arrazola, 2010).

Observou-se, nas entrevistas realizadas em Duque de Caxias, que os caminhos percorridos pelos titulares homens e mulheres para o cadastramento do PBF foram diversos, tendo em comum o contexto da pobreza. As mulheres entrevistadas tiveram maior influência do que outras pessoas já participantes que incentivaram o cadastramento, como amigas e familiares; além disso, a maioria teve encaminhamento pelo serviço de assistência social. Já entre os homens entrevistados, o conhecimento sobre a possibilidade de serem titulares não estava tão evidente, exceto para aqueles que tinham filhos.

O desconhecimento do direito ao PBF pelos homens titulares despertou a reflexão sobre a invisibilidade desse grupo. No estudo de Barbosa e Freitas (2013), as autoras enfatizaram que, usualmente, os homens encontram dificuldades ao acessar os serviços de assistência social, dado o seu papel tradicional de provedor dos meios de subsistência e da proteção da família. São, assim, associados à força e ao trabalho, não sendo reconhecidas, de imediato, suas possíveis fragilidades perante o mercado de trabalho e, consequentemente, as dificuldades deles para o sustento da família. Ainda de acordo com o texto de Barbosa e Freitas (2013), cabe a reflexão da invisibilidade dos homens pobres perante as políticas e programas sociais de combate à pobreza. As autoras enfatizam que normalmente os serviços de assistência social têm a expectativa de que a mulher seja a representante da família. Portanto, as fragilidades masculinas, de acesso à renda e ao trabalho, podem passar despercebidas perante o serviço. Ainda nessa reflexão, os Centros de Referência em Assistência Social (CRAS), que representam a rede de proteção social primária, conforme o estudo de Muniz (2011), são normalmente destinados a acolher as mulheres como representantes da família, com decoraçóes voltadas para o público 
feminino e atividades relacionadas à casa e artesanato - atividades estas não atrativas para os homens e nem mesmo para mulheres que buscam inserção no mercado de trabalho e não estão disponíveis apenas para atividades de cuidado.

Nesse sentido, dois casos chamaram a atenção no estudo $B$. Como as entrevistas foram realizadas nas casas dos informantes, foi possível ver de perto a situação de pobreza em que ambos viviam. Pequenas casas, com poucos móveis, o fogão sem gás para cozinhar, os tijolos empilhados do lado de fora da casa, improvisando um fogão a lenha, davam indícios da situação de pobreza mais grave. $\mathrm{O}$ conjunto dos relatos destes dois homens foi o mais expressivo com relação ao sofrimento causado pela miséria e pela escassez de alimentos. Antônio enfatizou, em sua fala, o sentimento de humilhação trazido pela condição de pobreza e as dificuldades enfrentadas para se obter ajuda:

a gente vê tanta pobreza em nossa vida que fica até com mais vergonha... Porque tem tanta gente que tem boas condiçóes, e é a que mais humilha, mais desfaz da gente né... Desfaz porque tem que morrer de fome mesmo, a gente é pobre mesmo, é isso aí! Eles falam que a gente é vagabundo, mas eles não sabem o que é a nossa situação (Antônio, estudo B).

Além da condição de extrema pobreza, Antônio demonstrou a fragilidade no acesso à rede social, devido a conflitos com familiares, contando principalmente com o apoio de amigos. No caso de Antônio, assim como para Sandro e Sebastião, entrevistados no âmbito do estudo B, é interessante notar o surgimento de expressóes de gratidão pelo recebimento do benefício do $\mathrm{PBF}$ :

"aí só agradecer mesmo o Estado por ter isso aî" (Sandro);

“o Bolsa Família pra mim foi uma benção” (Sebastião). 
Tais expressóes deixam transparecer um entendimento, por parte de alguns participantes, de que o PBF seria uma caridade ou favor do Estado, e não um direito da população. Esse sentimento sugere que os titulares não se percebiam cidadãos de direitos, fato encontrado também em outros estudos (Carneiro, 2015; Rego e Pinzani, 2013; Pinto, 2010).

Para os titulares que tinham filhos, a chegada até o PBF foi mais naturalizada. Havia um entendimento de que o benefício era destinado somente às famílias com crianças e, nestes casos, os entrevistados enfatizaram diversas vezes que recebiam o benefício "para os filhos", entendendo que a titularidade representava uma espécie de intermediação para que os filhos pudessem receber o recurso. Era a presença de filhos que justificava o recebimento do benefício, demonstrando o não reconhecimento de seus direitos ao recebimento do benefício do programa.

Percebe-se aqui um desconhecimento dos critérios de elegibilidade ao PBF, pois alguns dos entrevistados acreditavam que o principal critério para inclusáo era a presença de filhos, e náo a renda familiar, independentemente da presença de crianças e/ ou mulheres na composição familiar. A desinformação sobre as regras que regem o PBF também foi constatada no estudo de Pinto (2010), com mulheres titulares do PBF da periferia do Rio de Janeiro. De acordo com o autor, a maioria das entrevistadas tinha o conhecimento do programa pela escola, pela televisão, por meio dos familiares e de vizinhos.

No caso de Carlos, a busca pelo cadastramento foi realizada pela esposa. Como na data marcada ela não pôde comparecer ao CRAS, por motivo de doença, ele se apresentou e se tornou titular. Em sua fala, no entanto, ele apresentava aquele benefício como pertencendo à sua mulher, a quem cabia determinar seu uso no âmbito familiar.

Ressaltamos ainda que, para as mulheres, a inclusão no programa trazia a sensação de segurança, em função de que este 
representava um aporte financeiro regular. A análise das entrevistas indicou sentidos, como autonomia e liberdade, principalmente para aquelas que não exerciam atividades profissionais e que, anteriormente ao PBF, dependiam apenas da renda do companheiro/ marido ou ex-marido, fato também observado no estudo de Lago et al. (2014) e Santos et al. (2015). Assim foi para Eliane, entrevistada no âmbito do estudo A, que relatou que o recebimento do benefício proporcionou maior independência financeira, possibilitou também o planejamento de gastos e representou alívio, já que, antes de se tornar participante do PBF, dependia exclusivamente da pensão paga pelo ex-marido. Ela conta:

Porque daí eu não fico mais só dependente dele [ex-marido]. Ah sei lá... quando falta as coisas eu não preciso mais ligar pedindo, muitas das vezes eu ainda tenho dinheiro. Se eu preciso de alguma coisa ou elas [filhas], eu não preciso mais ficar pedindo dinheiro pra comprar. Ah não sei, só sei que é melhor (Eliane, estudo A).

Em alguns casos, a dependência financeira era acompanhada pela violência doméstica. Para Lúcia, sua situação de desemprego e de dependência financeira do companheiro a impediam de sair do que ela considerava uma "vida humilhante", e foi a segurança proporcionada pelo recebimento do benefício do PBF que garantiu a condição de se separar do marido e se libertar, como ela conta:

Antes eu não tinha renda alguma, eu vivia humilhada, apanhando, né? E era submissa a isso porque eu não tinha renda [...] aí eu me senti bem mais segura de me separar. Hoje eu vivo bem e as minhas filhas também (Lúcia, estudo A).

Histórias semelhantes à de Lúcia aparecem também em outros estudos que demonstram que, ao se tornarem titulares e consequentemente responsáveis pelo recurso do benefício, as mulheres adquirem 
maior autoconfiança, autoestima e autodeterminação (Moreira et al., 2012; Pires, 2012). Assim, o aumento da independência feminina pode significar uma mudança na dominação tradicional dos homens sobre elas, garantindo-lhes autonomia no que se refere ao controle de seus corpos, à sexualidade, ao direito de ir e vir, bem como o sentimento de indignação à violência (Costa, 2000).

Ser participante do PBF é valorizado no contexto da pobreza e especialmente da pobreza extrema, como mostram os dados dos dois estudos aqui apresentados. Porém, ao contrário do que possa parecer no âmbito do senso comum, a titularidade não é necessariamente uma situação confortável para os participantes. Luiza, por exemplo, informante do estudo A, expressou sua expectativa de que a titularidade fosse provisória e avaliou que o PBF poderia ser uma política melhor, se oferecesse aos titulares oportunidades de emprego e de qualificação. Depender do benefício para sobreviver trazia, para ela, segurança, por não depender exclusivamente da pensão do ex-marido para ajudar sua mãe, mas também angústia e inconformismo. Ela também contou, na entrevista, que tinha o sonho de arrumar emprego para que pudesse alugar uma casa para ela e sua filha, não precisando mais morar "de favor" na casa da mãe, e para poder se desligar do PBF, dando oportunidade a quem mais precisasse. Luiza se sentia incomodada com sua situação de vida e, embora fosse titular do programa, preferia repassar o dinheiro para a mãe, como uma forma de ajudar nas despesas da casa e não se tornar um "peso".

Corroborando com a entrevista acima, segundo dados do estudo realizado pelo Instituto Brasileiro de Análises Sociais e Econômicas, entre cinco mil famílias titulares do PBF de todo país (Ibase, 2008), a principal expectativa das titulares em relação ao PBF era a inserção no mercado de trabalho formal. No entanto, as ações governamentais associadas ao programa com foco na inserção produtiva são pouco recorrentes. Logo, a entrevista de Luiza 
contribui para refletir a situação daqueles participantes que buscam maior apoio do PBF para a inserção produtiva.

\section{Consideraçóes finais}

Este estudo buscou discutir as vivências dos participantes do $\mathrm{PBF}$ a partir de seus relatos sobre a forma como utilizavam o benefício e os sentidos atribuídos a ele. $\mathrm{O}$ uso desse direito, conforme mostram os dados dos dois estudos realizados em Duque de Caxias, foi aplicado essencialmente para a alimentação, sendo que a criança, quando era presente na família, se tornava prioridade. Mais que isso, o PBF é percebido pelos grupos entrevistados como uma política voltada para a criança, e não para a família - esta apenas a gestora dos recursos financeiros, que devem ser utilizados de uma forma considerada "correta", o que acompanha implicitamente o entendimento de que "o PBF é para as crianças".

Assim, embora o recebimento de um auxílio financeiro seja acompanhado de uma liberdade de escolha e uma inserção desejada na sociedade de consumo, o montante recebido náo deixa muita margem para escolhas mais "ousadas". O julgamento associado ao uso do benefício pode cercear o atendimento a outras demandas compreendidas como desvinculadas das necessidades mais imediatas das crianças.

A titularidade do PBF é preferencialmente delegada às mulheres, tendo em vista a noção de que as tarefas domésticas e o cuidado à família são culturalmente compreendidos como femininas. No entanto, nos dois estudos, tanto para as mulheres quanto para os homens, a criança permaneceu como ponto norteador do direcionamento do uso do recurso, considerando a alimentaçáo referida como prioritária.

Ainda que o PBF represente para os participantes uma mudança positiva, particularmente sob o aspecto da compra de gêneros alimentícios, o programa foi percebido pelos entrevistados 
como uma ajuda, que proporciona apenas a manutenção da vida em nível de subsistência.

Este estudo também nos leva a refletir que o benefício era entendido como insuficiente para de fato sair da condição de pobreza, o que seria alcançado de forma mais eficiente, segundo alguns dos entrevistados, por meio do acesso à formação profissionalizante e ao emprego formal.

Outro ponto que o capítulo destaca se refere à importância de reconhecer o homem como cidadão de direitos, tanto em nível macro das políticas quanto no cotidiano dos serviços públicos. Nesse aspecto, há que se desenvolver estratégias de captação e o seu acompanhamento na rede de atenção à saúde, priorizando os titulares do PBF. Não devemos esquecer também do cuidado integral no atendimento nutricional de homens titulares do PBF que chegam nos CRAS e nas unidades básicas de saúde, os quais, muitas vezes, não são concebidos imediatamente como possíveis participantes e titulares pelos serviços de assistência social, cujas fragilidades podem passar desapercebidas.

Quanto às mulheres, é essencial que políticas, programas e açóes, nos diferentes setores da esfera pública, reforcem sua autonomia e promovam melhores condiçóes, especialmente para aquelas de famílias mais vulneráveis.

Destacamos que ao optar pelo PBF como forma de superação da pobreza e da pobreza extrema, por meio da transferência de renda, o Brasil avançou na formulação de políticas sociais de combate à fome. Porém, outras açóes precisam ser desenvolvidas para que as famílias mais pobres possam, com efeito, alcançar melhores condiçóes de vida e cidadania.

Este estudo também reforça as vulnerabilidades e aspectos subjetivos de participantes do PBF, como o desconforto de alguns dos entrevistados pela "ajuda" vinda do programa e o sentimento de culpa sobre a possibilidade de efetivamente utilizarem o benefício 
como bem desejarem. Tais vulnerabilidades dificultam a construção da ideia de direitos sociais e, particularmente, do direito à saúde.

$\mathrm{Na}$ perspectiva da construção e consolidação do cuidado integral, no contexto da Atenção Básica, lócus privilegiado para o acompanhamento das condicionalidades de saúde, é fundamental refletir e discutir, junto às equipes, julgamentos morais que costumam estar presentes na sociedade em relação aos beneficiários do Bolsa Família. Faz-se necessário, ainda, enfatizar a importância de os profissionais considerarem as singularidades, as histórias de vida e as expectativas dos sujeitos participantes do PBF para a concretização dos direitos sociais. Ou seja, a integralidade do cuidado em saúde que abordamos neste capítulo, tendo como exemplo o uso dos benefícios e da titularidade de famílias atendidas pelo PBF, fala da importância da visão ampliada das necessidades de saúde dos sujeitos, com base nos diálogos estabelecidos entre eles e os profissionais que atuam na atenção nutricional nas unidades básicas de saúde, como pontuado por Alves e Mattos (2019).

Concluindo, os resultados deste estudo apontam a importância da escuta e da compreensão das vivências dos titulares e familiares participantes do PBF como caminho para o desenvolvimento de ações integrais e intersetoriais com vistas à promoção da saúde e da vida.

\section{Referências}

ALVES, K. P. S. e JAIME, P. C. “A Política Nacional de Alimentação e Nutrição e seu diálogo com a Política Nacional de Segurança Alimentar e Nutricional”. Ciênc. saúde coletiva, v. 19, n. 11, pp.4331-40, Rio de Janeiro, 2014. e MATTOS, R. A. "Atenção nutricional e a integralidade do cuidado em saúde". In Políticas de alimentação e nutrição. Rio de Janeiro: Atheneu, 2019, pp. 105-12.

BRASIL. Lei n. ${ }^{\circ}$ 10.836, de 09 de janeiro de 2004. Cria o Programa Bolsa Família e dá outras providências. Diário Oficial da União. Brasília, 2004. 
Disponível em: http://www.planalto.gov.br/ccivil_03/_ato2004-2006/2004/ lei/l10.836.htm. Acesso em: jul. 2015.

. Ministério do Desenvolvimento Social e Combate à Fome. CAMPELLO, T. et al. (orgs). O Brasil sem Miséria. Brasília: MDS, 2014.

. Decreto n.o 8.794, de 29 de junho de 2016. Altera o Decreto n. ${ }^{\circ}$ 5.209, de 17 de setembro de 2004, que regulamenta a Lei n. ${ }^{\circ} 10.836$, de 9 de janeiro de 2004, que cria o Programa Bolsa Família, e o Decreto n. ${ }^{\circ}$ 7.492, de 2 de junho de 2011, que institui o Plano Brasil Sem Miséria, e dá outras providências. Diário Oficial da União. Brasília, 2016. Disponível em: http://www.planalto.gov. br/ccivil_03/_ato2015-2018/2016/decreto/D8794.htm. Acesso em: mar. 2016.

Ministério da Cidadania. Secretaria Especial do Desenvolvimento Social. Programa Bolsa Família. Disponível em: http://mds.gov.br/assuntos/ bolsa-familia/o-que-e/como-funciona. Acesso em: abr. 2019.

BARBOSA, D. O. e FREITAS, R.C.S. "A invisibilidade dos homens na proteção social básica: um debate sobre gênero e masculinidades". OPSIS, v. 13, n. 2, pp. 58-83, Cataláo, jul./dez. 2013.

BARDIN, L. Análise de Conteúdo. Trad. Luís Antero Reto e Augusto Pinheiro. São Paulo: Edições 70, 2011.

BOURDIEU, P. A distinção: crítica social do julgamento. 1 ed. São Paulo: Edusp; Porto Alegre: Zouk, 2007.

BURLANDY, L. "Transferência Condicionada de Renda e segurança alimentar e nutricional”. Ciência \& Saúde Coletiva, v. 12, n. 6, pp.1441-51, Rio de Janeiro, dez. 2007.

CARLOTO, C. M. e MARIANO, S. A. "No meio do caminho entre o privado e o público: um debate sobre o papel das mulheres na política de assistência social”. Rev. Estudos Feministas, v. 18, n. 2, pp. 451-71, Florianópolis, ago. 2010.

CARNEIRO, D. F. Práticas alimentares e estratégias de enfrentamento da insegurança alimentar e nutricional de famílias em vulnerabilidade social. (dissertação). Universidade Federal do Paraná, 2015.

CEPAL - COMISSÃO ECONÔMICA PARA AMÉRICA LATINA E CARIBE. Panorama social de América Latina. Santiago de Chile: Naçôes Unidas, 2011, p. 262. Disponível em: http://www.cepal.org/publicaciones/xml/9/41799/ PanoramaSocial2010.pdf. Acesso em jul. 2015.

COSTA, A. A. Gênero, poder e empoderamento das mulheres. Núcleo de Estudos Interdisciplinares sobre a Mulher (Neim/Ufba), 2000.

DUQUE-ARRAZOLA, L. S. "O sujeito feminino nas políticas de assistência social”. In MOTA, A. E. (org) O mito da assistência social: ensaios sobre o Estado, política e sociedade. 4 ed. São Paulo: Cortez, 2010. 
IBASE. Repercussóes do Programa Bolsa Família na Segurança Alimentar e Nutricional das famílias beneficiadas. Relatório técnico, preliminar. Rio de Janeiro, jun. 2008.

LAGO, M. C. S. et al. "Narrativas sobre o Programa Bolsa Família em Florianópolis”. Estud. sociol. Araraquara, v. 19, n. 37, pp. 471-90, jul.-dez. 2014.

MARIANO, S. A. "Traduçôes político-culturais de gênero na política de assistência social: paradoxos e potencialidades para o empoderamento das mulheres no Programa Bolsa Família”. Revista Gênero, v. 9, n. 1, pp. 155-87, Niterói, 2008.

e CARLOTO, C. M. "Gênero e combate à pobreza: Programa Bolsa Família”. Rev. Estudos Feministas, v. 17, n. 3, pp. 901-8, Florianópolis, dez. 2009. e . "Aspectos diferenciais da inserçáo de mulheres negras no Programa Bolsa Família”. Soc. Estado, v. 28, n. 2, pp. 393-417, Brasília, ago. 2013.

MINAYO, M.C.S. et al. (orgs.). Pesquisa Social: teoria, método e criatividade. 31 ed. Petrópolis (RJ): Editora Vozes, 2012, p. 108.

MOREIRA, N.C. et al. "Empoderamento das mulheres beneficiárias do Programa Bolsa Família na percepção dos agentes dos Centros de Referência de Assistência Social". RAP, v. 46, n. 2, pp. 403-23, Rio de Janeiro, mar./ abr, 2012.

PINTO, I. V. Percep̧ção dos titulares do Programa Bolsa Família e as repercussóes em suas condiçôes de vida: Um estudo no Centro de Saúde Escola Germano Sinval Faria, em Manguinhos, RJ, 2009. (dissertação). Fundação Oswaldo Cruz, 2010.

PIRES, A. "Orçamento familiar e gênero: percepçôes do Programa Bolsa Família”. Cad. Pesqui., v. 42, n. 145, pp. 130-61, São Paulo, abr. 2012.

REGO, W. L. e PINZANI, A. Vozes do Bolsa Familia: autonomia, dinheiro e cidadania. São Paulo: Unesp, 2013.

RIGON, Silvia do Amaral et al. "Desafios da nutrição no Sistema Único de Saúde para construção da interface entre a saúde e a segurança alimentar e nutricional". Cad. Saúde Pública, v. 32, n. 3, pp. 1-10, Rio de Janeiro, 2016.

ROSINKE, J. G. et al. "Efeitos sociais e econômicos para o desenvolvimento local através das contribuiçóes do Programa Bolsa Família no município de Sinop-MT no período de 2004 a 2009”. Interaçôes, v. 12, n. 1, pp. 77-88, Campo Grande, 2011.

SANTOS, L. N. et al. "Estratégias de acesso aos alimentos pelas famílias titulares de direito do Programa Bolsa Família”.Divers@Revista Eletrônica Interdisciplinar, v. 8, n. 2, pp. 84-94, Matinhos, jul./dez. 2015.

SOUZA, A. R. L. e RÉVILLION, J. P. P. "Novas estratégias de posicionamento na fidelizaçáo do consumidor infantil de alimentos processados". Ciência Rural, v. 42, n. 3, mar. 2012. 
98 Alimentação e nutrição na Atenção Básica

ZELIZER, V. "O significado social do dinheiro". In MARQUES, R. e PEIXOTO, J. (orgs). A nova sociologia econômica: uma antologia. Portugal: Celta Editora, 2003, pp. 125-65. 